\title{
Caracterização de pellets plásticos na Praia do Tombo, município do Guarujá, SP, Brasil
}

\author{
Gabriel Hirata $^{\text {I }}$; Ednilson Viana ${ }^{2}$; Homero Fonseca Filho ${ }^{2}$; Helene Mariko Ueno ${ }^{2}$; André Felipe \\ Simões ${ }^{2}$ \\ 凹gabriero@gmail.com
}

1. Universidade Federal de Pernambuco, Av. Prof. Moraes Rego, 1235 - Cidade Universitária, Recife, Brasil. 2. EACH/USP - Escola de Artes, Ciências e Humanidades, Rua Arlindo Bettio, 1000, São Paulo, Brasil.

Histórico do Artigo:

Recebido: 22 de junho de 2017

Aceito: 11 de outubro de 2017

Publicado: 5 de janeiro de 2018

Resumo: Pellets plásticos são grânulos utilizados como matéria prima para a produção de objetos de plástico pela indústria de transformação. Ao serem transportados, estes pellets se perdem e podem alcançar o ambiente marinho. Nesse contexto, buscou-se avaliar qualitativamente e quantitativamente os pellets que chegam à Praia do Tombo, Guarujá (SP). Para tanto, calculou-se a taxa de entrada de pellets para cinco pontos de coleta na praia. 0s resultados mostraram que a praia recebe quantidades consideráveis de pellets plásticos, totalizando uma taxa de 21 a 26 pellets por $\mathrm{m}^{2}$. 0 formato cúbico achatado foi predominante e $62 \%$ tinham tons mais claros, como branco e bege translúcidos, o que indica uma entrada recente no ambiente. Como os pellets podem apresentar contaminação por POPs, a presença deles na Praia do Tombo que pode ser mais um desafio para a sustentabilidade no ambiente costeiro.

Palavras-chave: Caracterização de pellets, Resíduos Sólidos, Ambiente Marinho, Contaminação.

\section{Characterization of plastics pellets in the Tombo Beach, Guarujá municipality, SP, Brazil}

Abstract: Pellets are plastic granules used as raw material for the production of plastic object by the processing industry. When transported, these pellets are lost and may reach the marine environment. In this context we sought to evaluate quantitatively and qualitatively the pellets that arriving at Tombo Beach, Guarujá (SP). In order to do this,it was calculated the entry pellets rate in five sampling points on the beach. The results showed that the beach receives considerable amounts of plastic pellets, totaling 21 to 26 pellets per $\mathrm{m}^{2}$. The cuboid form was predominant and $62 \%$ had lighter shades, such as translucent white and beige, which indicates a recent entry into the environment. As the pellets can be contaminated by P0Ps, their presence on the beach of Tombo can be a challenge for sustainability in the coastal environment.

Keywords: Characterization of pellets; Solid Waste; Marine Environment; Contamination.

\section{Caracterización de pellets plásticos en la Playa de Tombo, municipio de Guarujá, SP, Brasil}

Resumen: Los pellets plásticos son gránulos utilizados como materia prima para la producción de objetos de plástico en la industria. Al ser transportados, estos pellets se pierden o se lanzan en el ambiente marino. En ese contexto, se buscó evaluar cualitativa y cuantitativamente los pellets que llegan a la playa de Tombo, Guarujá (SP). Para ello, se calculó la tasa de entrada de pellets en cinco puntos de recolección en la playa. Los resultados mostraron que la playa recibe cantidades considerables de pellets plásticos, obteniéndose una tasa de 21 a 26 
pellets por $\mathrm{m} 2$, siendo el formato cúbico aplanado el predominante. De las muestras recolectadas el $62 \%$ presentaban tonos claros, como blanco y beige translúcidos, lo que indica una entrada reciente en el ambiente. Como los pellets pueden presentar contaminación por Contaminantes Orgánicos Persistentes (COP), la presencia de ellos en la playa de Tombo puede ser un desafío más para la sostenibilidad en el ambiente costero.

Palabras clave: Caracterización de pellets, Residuos sólidos, Medio ambiente marino, Contaminación.

\section{INTRODUÇÃo}

0 Programa das Nações Unidas para o Meio Ambiente define lixo marinho como qualquer resíduo sólido manufaturado ou industrializado que tenha sido descartado, depositado ou abandonado no ambiente marinho ou costeiro, por qualquer fonte geradora (UNEP, 2005). Estes resíduos podem apresentar tipologias muito variadas como plásticos, metais, papel, papelão, vidro, orgânicos, dentre outros.

Frequentemente, o lixo marinho é encontrado próximo à sua fonte, mas também pode ser transportado até longas distâncias pelos ventos e correntes marítimas, no substrato dos oceanos e das águas costeiras ou flutuando na coluna d'água. Isso explica a sua ocorrência em locais remotos como praias desertas, ilhas oceânicas ou recifes costeiros (ARAÚJ0, 2003; TOURINH0, 2007; UNEP, 2005; WIND0M, 1992).

0 lixo marinho que atinge as zonas costeiras pode ser proveniente de fontes terrestres ou marinhas. Dentre as fontes terrestres citam-se os resíduos de drenagem de rios e lançamento de esgotos e a própria geração de resíduos sólidos nas cidades costeiras, bem como aqueles resíduos deixados pelos frequentadores das praias. Por outro lado, os resíduos de fontes marinhas tem origem nas plataformas oceânicas e por navios e barcos de pesca (IVAR D0 SUL, 2005). Segundo a referida autora, as principais fontes de lixo marinho são terrestres, representando $80 \%$ do lixo presente nos oceanos.

0 lixo marinho chega nos oceanos sob diferentes tamanhos e formas, desde sacolas plásticas e garrafas até grânulos de $1 \mathrm{~mm}$ de diâmetro, os chamados pellets que são a forma básica de comercialização do plástico enquanto matéria-prima. Os pellets são produzidos sob diversas formas, em especial, esféricas, ovoides e cilíndricas e tamanhos de 1 a $5 \mathrm{~mm}$, e cores, geralmente claras, brancas ou transparentes, dependendo de sua composição química e de seu propósito de uso final (MANZAN0, 2009). 
0s pellets plásticos, sob a forma de matéria prima, quando chegam às fábricas, são transformados em canetas, réguas, sacolas, copinhos, garrafas, baldes, mamadeiras, isolantes de fiação, bolas, bonecas; enfim, todos os milhares de produtos presentes no cotidiano. 0 referido processo cresceu, acintosamente, a partir de 1945, ou seja, a partir do final da $2^{\mathrm{a}}$ Guerra Mundial (1939-1945), quando os polímeros começaram a ser produzidos em larga escala, provocando uma mudança estrutural na atividade humana.

As resinas mais utilizadas no mercado para a fabricação de pellets normalmente contêm polietileno, polipropileno e poliestireno (USEPA, 1993), o que lhes confere resistência ao calor, ao ar e à água. Por outro lado, a ação das radiações solares transforma os pellets em partículas cada vez menores, mas que mantêm as características originais. Por essas razões, a quantidade desse resíduo nos oceanos cresce continuamente (MANZAN0, 2009).

Depois de produzidos, os grânulos são embalados e transportados até as indústrias de transformação para serem moldados nas mais variadas formas. Em vários pontos da cadeia produtiva do plástico, os pellets podem ser perdidos, de maneira não intencional, na natureza e chegar até os oceanos. 0 caminho até o ambiente aquático pode ser feito por meio das tubulações de efluentes urbanos e industriais, no caso dos produtores e processadores de grânulos; de vazamentos em caminhões, vagões de trem e barcos, durante o transporte; como rejeitos de atividades realizadas em mar aberto como lavagem de porões de navios e despejos de resíduos de barcaças; além de eventuais acidentes com navios cargueiros durante as operações de manuseio de carga nos portos ou durante o transporte de carga pelo mar (USEPA, 1993; HESKETT et al., 2012; TURNER; HOLMES, 2011). Consequentemente, os pellets estão presentes em todos os oceanos e em diversas praias do mundo e têm sido relatados desde a década de 1970.

Pellets de plástico tem sido encontrados em várias praias ao redor do mundo pela sua capacidade de serem transportados por longas distâncias, pela durabilidade dos polímeros e pelo aumento de sua produção(HESKETT et al., 2012). No ambiente marinho, os pellets flutuantes podem, ainda, estar associados a outro problema: a migração de espécies exóticas aderidas a sua superfície, através da incrustação de propágulos, bactérias e algas, que podem causar desequilíbrios ecológicos para ecossistemas de outras regiões (MANZANO, 2009). Também podem ser ingeridos por animais costeiros e marinhos por se confundirem com algas, ovos ou larvas. A ingestão de pellets pode bloquear o trato intestinal, reduzir a absorção de nutrientes ou ainda conferir saciedade em animais, como peixes e aves, reduzindo a busca por 
alimento e levando-os à morte por inanição (END0 et al., 2005; USEPA, 1993; TURNER; HOLMES, 2011).

Segundo a Environmental Protection Agency - EPA (1993), as aves marinhas são os animais que mais ingerem pellets. Cerca de um quarto das espécies de aves marinhas tiveram ingestão de pellets comprovada (USEPA, 1993). Além disso, os pellets podem veicular compostos químicos tóxicos adsorvidos à sua superfície (LE et al., 2016; RIOS et al, 2007; TANIGUCHI et al, 2016). Por exemplo, poluentes orgânicos persistentes (POPs) como 0 diclorodifeniltricloroetano (DDT), bifenil policlorado (PCB) e monofenóis se adsorvem aos grânulos em concentrações que podem ser um milhão de vezes maiores do que a concentração destes compostos dissolvidos na água. Assim, a ingestão desses pellets pode acarretar efeitos adversos associados aos P0Ps, como interferentes endócrinos, prejudicando o desenvolvimento e/ou a reprodução dos organismos marinhos que os consomem, e, indiretamente, em humanos, já que muitos desses organismos, em especial os peixes, são comuns na dieta humana (END0 et al., 2005; HESKETT et al., 2011; HOLMES, TURNER, THOMPSON, 2012).

Os pellets são resíduos diferenciados, com morfologia típica e particularidades quanto à dinâmica de perda para o mar, comportamento hidrodinâmico e potencial de impacto ambiental em relação a outros resíduos. Para reduzir a dispersão desses grânulos no oceano e litoral, deve haver mudanças na estocagem, manuseio e transporte deste material (MANZANO, 2009; PEREIRA, OLIVEIRA, TURRA, 2011; PIANOWSKI, 1997).

No Brasil, pouco se conhece a respeito de estratégias de gestão direcionadas para facear o problema dos pellets plásticos em praias. Isto se reflete na escassez de práticas e políticas, públicas e/ou privadas, desenvolvidas e na falta de marcos legais acerca do assunto. Assim, o objetivo do estudo foi investigar a ocorrência e caracterização de pellets plásticos em uma praia do litoral paulista, próxima ao Porto de Santos.

\section{MATERIAL E MÉTODOS}


Trata-se de um estudo descritivo exploratório para caracterizar os pellets que chegam à Praia do Tombo, localizada no município do Guarujá, litoral sul do Estado de São Paulo (Figura 1), sob as coordenadas geográficas aproximadas $24^{\circ} 00^{\prime} 50^{\prime}$ 'S; $46^{\circ} 16^{\prime 2} 22^{\prime \prime} \mathrm{W}$, sob influência da atividade portuária de Santos, principal porto do Brasil, instalado no Canal do Estuário de Santos.

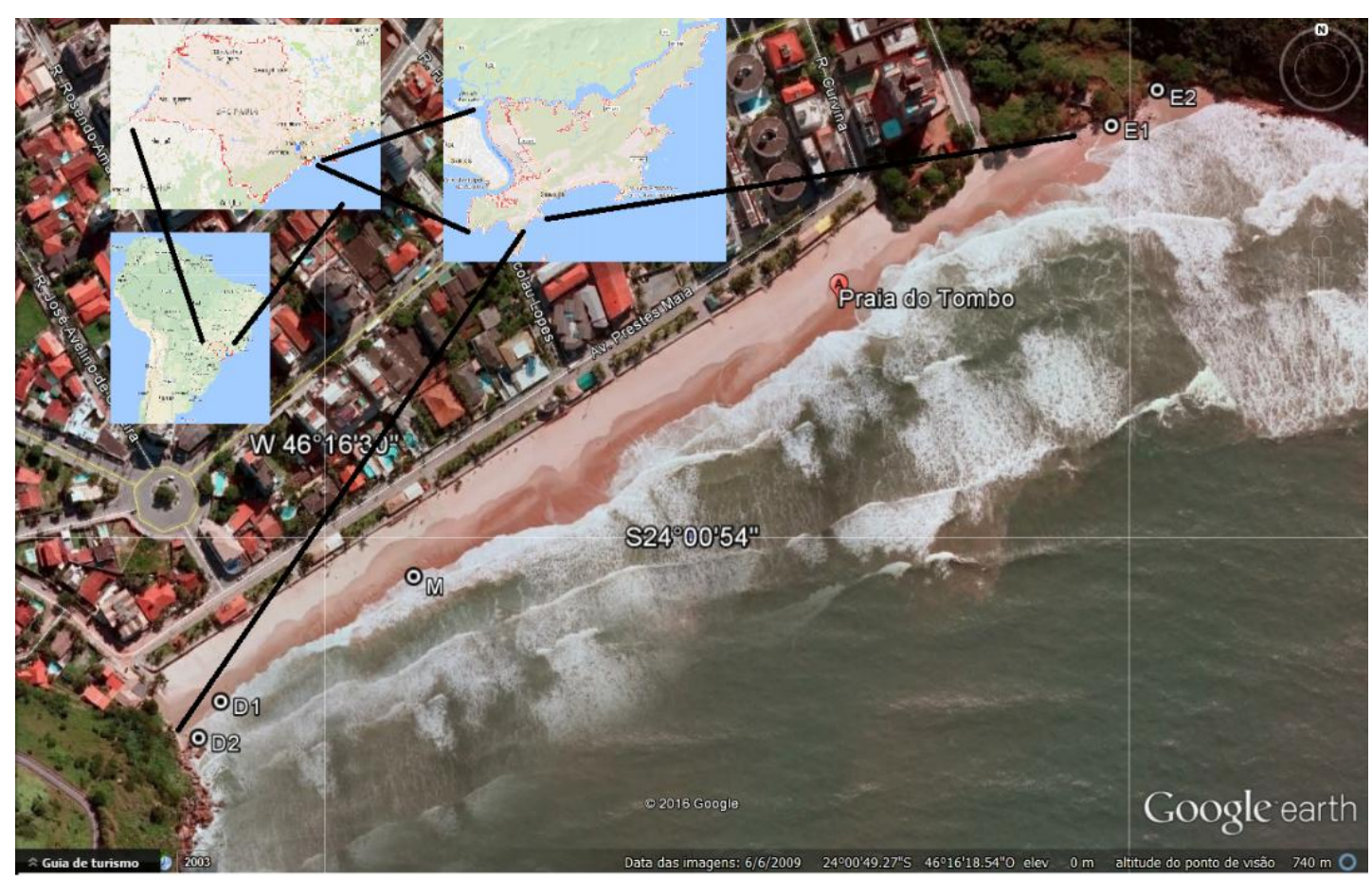

Figura 1. Localização dos pontos de amostragem na Praia do Tombo, município do Guarujá - Estado de São Paulo.

Fonte: Google Earth, preparado pelos autores.

A praia do Tombo tem aproximadamente $856 \mathrm{~m}$ de extensão, com intensa urbanização e atividade de surf. Situa-se entre o Morro da Caixa d’Água e o Morro do Forte, e recebeu este nome devido à sua formação geológica, que junto com as fortes ondulações, formam buracos na areia que podem provocar "tombos" aos banhistas.

A metodologia de coleta das amostras foi baseada em protocolos internacionais descritos por Heskett et al. (2012). Os grânulos plásticos foram coletados na linha da preamar mais recente das praias. Foram estabelecidos aleatoriamente, 5 pontos de coleta, sendo 2 na região Leste da praia (E1 e E2), 2 na região 0este (D1 e D2), e 1 próximo a região central da praia, como apresentado na Figura 1 e no link de Internet na própria figura. Estes pontos 
foram visitados diariamente durante o período de coleta de dados respeitando a Tábua de Marés do Porto de Santos.

A zona de deixa da maré representa a altura máxima que a água do mar avançou em direção ao continente durante a preamar superior, trazendo consigo os "novos" pellets e outros resíduos à praia. Um método simples para averiguar essa altura máxima atingida pela água, consiste em fazer um traçado na areia da praia em direção perpendicular ao mar, durante a última baixa-maré do dia anterior a cada coleta. Desse modo, à medida que a maré sobe, durante o dia seguinte, ela apaga a linha tracejada na areia. A linha de deixa da maré pode ser identificada a partir da altura em que a linha tracejada se manteve, indicando que a água não atingiu tal ponto.

Em cada ponto de coleta, foi estabelecida uma área de um metro quadrado na linha de deixa da maré, onde eram recolhidos todos os pellets visíveis na superfície da areia. Para recolher as amostras foram utilizadas pinças de aço inoxidável, previamente esterilizadas. As pinças foram mantidas em papel alumínio até o momento de sua utilização nas coletas. As amostras também foram embrulhadas em papel alumínio até serem analisadas.

Para a análise qualitativa, foram sorteados, aleatoriamente, 100 pellets de cada ponto para serem analisados morfologicamente. Para coletas com quantidade total inferior a 100 pellets, analisou-se o total coletado da amostra. 0s pellets plásticos foram, então, separados a olho nu em diferentes categorias de acordo com seus formatos e colorações, que podem sugerir possíveis fontes e tempo de residência destes resíduos no ambiente.

Os dados obtidos referentes a quantidade de pellets coletados foram submetidos a análise de variância (ANOVA), utilizando o software Excel com o suplemento Action. A análise de variância tem por objetivo comparar a média de várias populações (no caso dessa pesquisa são os pontos de estudo), se são iguais (hipótese nula) ou se possuem diferenças significativas (hipótese alternativa). Para as comparações múltiplas foi utilizado o teste de Tukey. 0 nível de significância em ambos os testes foi considerado de 5\%.

\section{RESULTADOS E DISCUSSÃ0}


Entre os dias 16 e 19 de outubro de 2012, foram coletados um total de 880 grânulos plásticos, distribuídos entre os 5 pontos de amostragem da Praia do Tombo (Tabela 1).

Tabela 1 - Número de pellets $/ \mathrm{m}^{2}$, média e totais encontrados por dia, por ponto de coleta na Praia do Tombo. Guarujá, SP

\begin{tabular}{|c|c|c|c|c|c|c|c|}
\hline \multirow{2}{*}{ Data } & \multicolumn{5}{|c|}{ Pontos de amostragem } & \multirow{2}{*}{ Total } & \multirow{2}{*}{ Média } \\
\hline & $\mathrm{D} 2$ & D1 & $\mathrm{M}$ & El & $\mathrm{E} 2$ & & \\
\hline 16/out & 13 & 21 & 43 & 25 & 145 & 247 & 49,1 \\
\hline $17 /$ out & 16 & 34 & 69 & 23 & 88 & 230 & 46,0 \\
\hline 18/out & 8 & 12 & 83 & 26 & 78 & 207 & 41,4 \\
\hline $19 /$ out & 11 & 17 & 75 & 21 & 72 & 196 & 39,2 \\
\hline Total & 48 & 84 & 270 & 95 & 383 & 880 & \\
\hline Média & 12,0 & 21,0 & 67,5 & 23,8 & 95,8 & & \\
\hline $\begin{array}{l}\text { Desvio } \\
\text { padrão }\end{array}$ & 3,37 & 9,42 & 17,31 & 2,22 & 33,49 & & \\
\hline Distância (m) & 12 & 34 & 180 & 716 & 743 & & \\
\hline
\end{tabular}

Fonte: 0s autores, 2017.

Pode-se observar que a quantidade e a média de pellets coletados variou de 247 no primeiro dia para 196 no último dia. Considerando todo o período de coleta, a densidade mínima de pellets foi de 8 pellets/m² no ponto D2 em 18/10/2012, e a densidade máxima foi de 145 pellets/m² no ponto E2 em 16/10/2012 (Tabela 1).

A quantidade de pellets coletados variou em função das datas de coleta, em cada ponto de amostragem e na comparação entre os pontos de coleta (Gráfico 1). Os dados dos pellets coletados em cada ponto de estudo (D2, D1, M, E1 e E2) foram submetidos a análise de variância. De acordo com a análise de dados, o p-valor obtido foi de $0,004 \%$, ou seja, menor do que 5\%, o que indica que existe diferença significativa entre as médias dos pontos de coleta.

Gráfico 1 - Quantidade de pellets $/ \mathrm{m}^{2}$ por datas e por ponto de coleta, Praia do Tombo. Guarujá, SP, Brasil. 


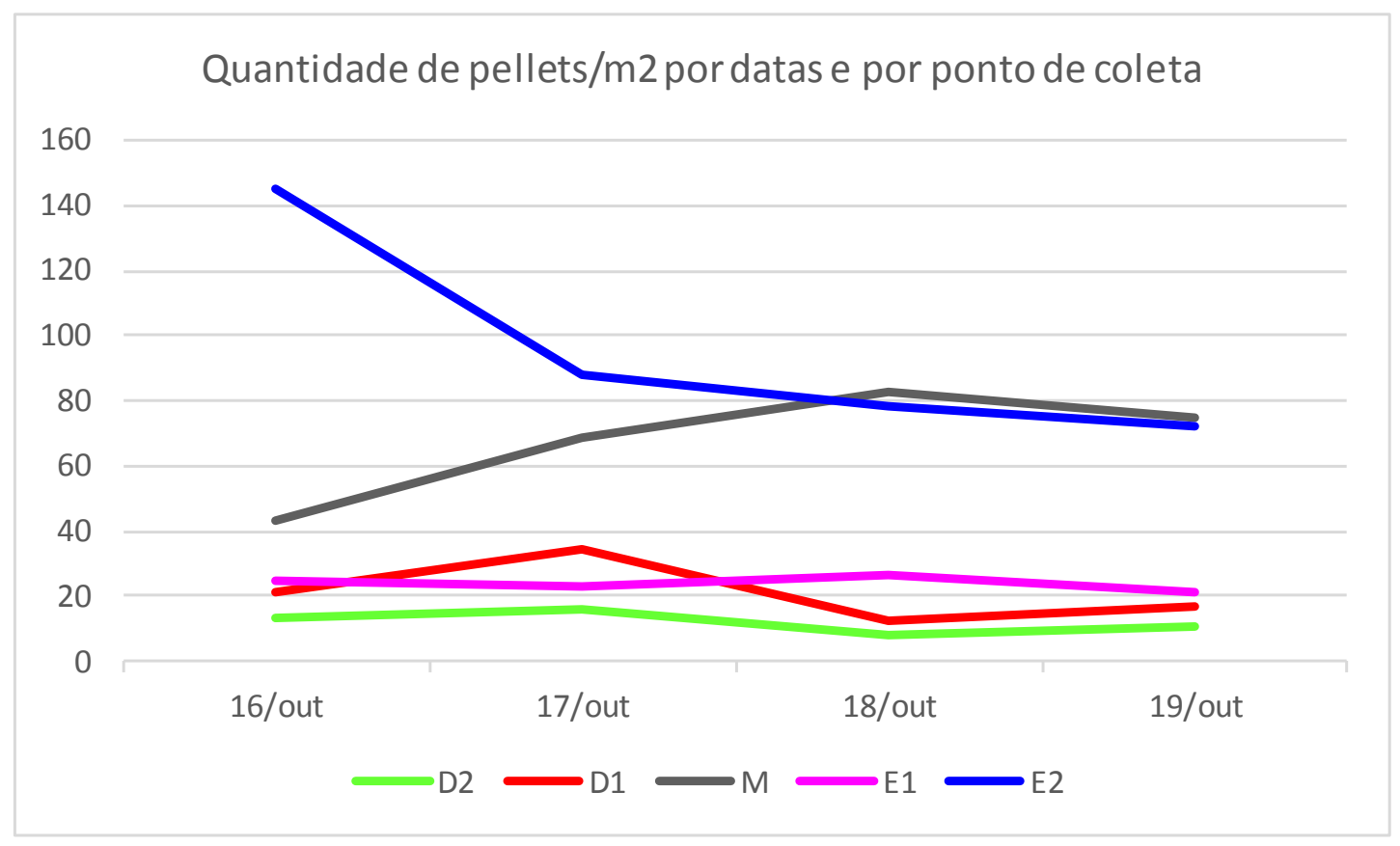

Fonte: Os autores, 2017.

Para identificar quais são os pontos que possuem diferença significativa, realizou-se 0 processo de comparações múltiplas (mais especificamente o teste de Tukey).Os pares que tiveram diferença significativa são destacados na Tabela 2 e corresponderam a E2-D1, M-D1, E2-D2, M-D2, E2-E1 e M-E1.

Tabela 2 - Comparações entre os pontos de estudo (D2, D1, M, El e E2) através do intervalo de confiança da diferença de médias

\begin{tabular}{ccccc}
\hline Níveis & Centro & Limite.Inferior & Limite.Suberior & P-valor \\
\hline D2-D1 & -9 & $-47,15$ & 29,15 & 0,946451783 \\
E1-D1 & 2,75 & $-35,40$ & 40,90 & 0,999387649 \\
E2-D1 & 74,75 & 36,60 & 112,90 & 0,000185546 \\
$M$ M-D1 & 46,5 & 8,35 & 84,65 & 0,013758088 \\
E1-D2 & 11,75 & $-26,40$ & 49,90 & 0,872279276 \\
E2-D2 & 83,75 & 45,60 & 121,90 & $5,27824 E-05$ \\
$M-D 2$ & 55,5 & 17,35 & 93,65 & 0,003353595 \\
E2-E1 & 72 & 33,85 & 110,15 & 0,00027607 \\
$M-E 1$ & 43,75 & 5,60 & 81,90 & 0,02114763 \\
M-E2 & $-28,25$ & $-66,40$ & 9,90 & 0,202608398 \\
\hline
\end{tabular}

Fonte: Os autores, 2017. 
0 Gráfico 2 apresenta o intervalo de confiança em relação a diferença de médias para os dados coletados, onde pode se visualizar os pares com diferença significativa e mencionados acima.

Grãfico 2 - Intervalos de Confiança da diferença de médias.

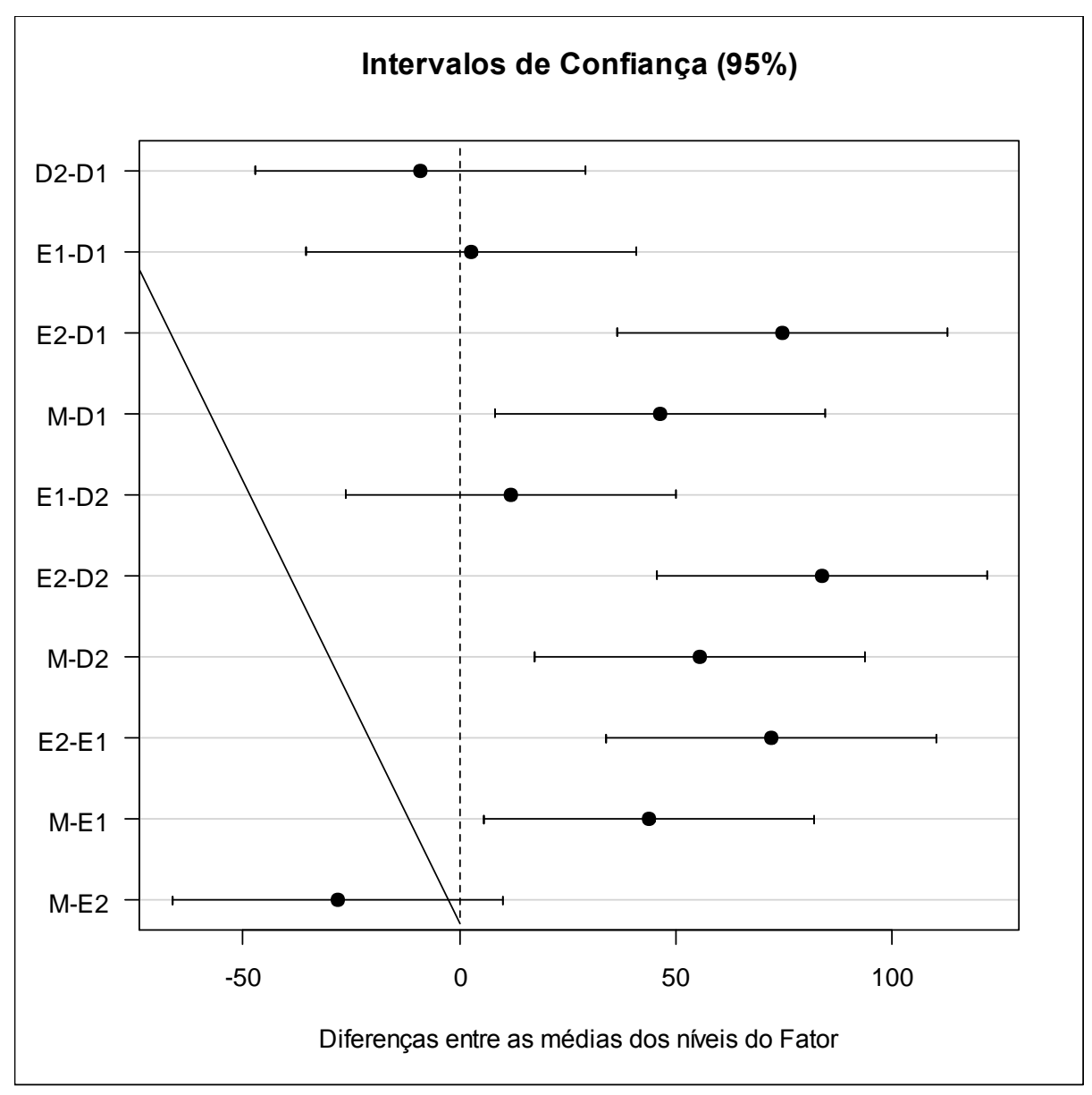

Fonte: Os autores, 2017.

Os resultados evidenciados pelos Gráficos 1 e 2, juntamente com os resultados da Análise de Variância apresentados na Tabela 2, mostram que os pontos de coletas poderiam ser agrupados em dois grandes grupos, sendo que os que se assemelham são: (D2, D1 e E1) e (M, $\mathrm{E} 2)$.

A densidade elevada de pellets no ponto de coleta E2 pode ser explicada pelo fato deste ponto estar localizado em uma área menos acessível aos banhistas, o que evita que os grânulos sejam soterrados pelo pisoteio. Segundo Pianowski (1997), quando as praias são mais preservadas, os pellets são encontrados mais trivialmente. 
0 segundo ponto com maior concentração de pellets foi o ponto $\mathrm{M}$, onde foram coletados de 43 a 83 pellets $/ \mathrm{m}^{2}$. Juntos, os pontos E2 e M representam, aproximadamente, 75\% do total de pellets recolhidos.

Nos pontos de coleta El e D1 foi coletado o total de, respectivamente, 95 e 84 pellets. 0 ponto de coleta El, situado em área mais frequentada por banhistas, foi onde se observou a maior homogeneidade de taxa de entrada dos grânulos, com variação de 21 a 26 pellets $/ \mathrm{m}^{2}$, média de 23,8 e desvio padrão de 2,2. 0 ponto D2 correspondeu à menor taxa de grânulos coletados, ou seja, de 8 a 16 pellets $/ \mathrm{m}^{2}$, com média de 12,0 e desvio padrão de 3,4.

Manzano (2009) alerta para a possibilidade da taxa de entrada de pellets ficar subestimada em praias frequentadas por turistas e praticantes de esporte. Isso pode ter ocorrido na Praia do Tombo, embora seja uma suspeita, onde os frequentadores podem soterrar os pellets, mas também porque existe trabalho de limpeza com rastelos na linha de deixa para a retirada de resíduos deixados pelos frequentadores da praia, o que pode retirar ou deslocar os pellets.

Durante o período da pesquisa a agitação do mar estava fraca, com ondas que não ultrapassaram 1,5 m de altura. Em dias com ondas maiores que dois metros, pode ocorrer maior taxa de entrada de pellets, como verificou Manzano (2009) na Enseada de Santos, onde após um período de agitação no mar houve um aumento significativo de deposição de pellets, chegando a 377 pellets $/ \mathrm{m}^{2}$, considerando que a média era de 102 pellets $/ \mathrm{m}^{2}$.

A variação da taxa de entrada de pellets nos pontos de coleta durante os dias analisados foi de 196 a 247 pellets no total, resultando, em média, 220 unidades por dia. Como este resultado leva em conta os 5 pontos de coleta somados, observou-se que, em média, chegam 220 pellets por dia em uma área de $5 \mathrm{~m}^{2}$ na Praia do Tombo, em Guarujá, balneário tradicional de São Paulo. Quando se considera a extensão da praia estudada e a deposição de pellets em função diária ou ao longo do tempo, verifica-se que a quantidade de pellets que pode estar sendo ali depositada é significativa e por consequência preocupante, especialmente em algumas épocas do ano. Manzano (2009) encontrou diferenças sazonais, com maior deposição de pellets nas praias durante o outono e inverno do que na primavera e verão. A grande movimentação de embarcações, aliada à grande presença de indústrias petroquímicas na região, possibilitam a emissão de pellets e outros resíduos no ambiente (MANZAN0, 2009).

Os dados obtidos mostram que a Praia do Tombo no Guarujá recebe quantidade considerável de pelletse aponta para a potencial deposição destes resíduos neste local, alertando para os possíveis prejuízos ao meio ambiente, em especial à fauna e à flora locais. 
Embora a perda de matéria-prima possa ser desprezível, considerando a escala de uso de pellets, os impactos aos organismos da região devem ser considerados, devido à toxicidade que este material pode apresentar, inclusive ao ser humano. A análise do formato dos pellets encontrados na praia do Tombo foi feita para 463 pellets (Tabela 3).

Tabela 3 - Quantidade de pellets encontrados em função de seus formatos e em função dos pontos de coleta de dados. Praia do Tombo, Guarujá, SP, Brasil.

\begin{tabular}{ccccccccc}
\hline Ponto & Retangular & Cúbico & $\begin{array}{c}\text { Cilíndrico } \\
\text { grosso }\end{array}$ & $\begin{array}{c}\text { Cilíndrico } \\
\text { fino }\end{array}$ & $\begin{array}{c}\text { Cilíndrico } \\
\text { achatado }\end{array}$ & $\begin{array}{c}\text { Esférico } \\
\text { achatado }\end{array}$ & 0vóide & Disforme \\
\hline El & 4 & 7 & 3 & 7 & 61 & 11 & 6 & 1 \\
E2 & 0 & 4 & 2 & 4 & 73 & 3 & 8 & 6 \\
M & 0 & 18 & 2 & 1 & 71 & 4 & 2 & 2 \\
D1 & 0 & 7 & 6 & 2 & 61 & 12 & 9 & 3 \\
D2 & 1 & 7 & 3 & 3 & 38 & 3 & 5 & 3 \\
\hline Total & 5 & 43 & $\mathbf{1 6}$ & $\mathbf{1 7}$ & $\mathbf{3 0 4}$ & 33 & 30 & $\mathbf{1 5}$ \\
\hline
\end{tabular}

Fonte: Os Autores, 2015

Os dados obtidos mostraram 8 formatos recorrentes (Figura 2) e considerando todos os pontos de coleta, $66 \%$ dos pellets eram cilíndricos-achatados, com destaque para os pontos E2 e M, que apresentaram, respectivamente, $73 \%$ e $71 \%$ dos pellets com essa forma. 0 formato menos frequente foi o disforme (15 pellets), atribuído aos pellets não classificáveis em nenhum dos formatos anteriores, seja por desgaste ou defeito de fabricação. Essa variação de formatos sugere a existência de fontes variadas desse material (MANZAN0, 2009) . 


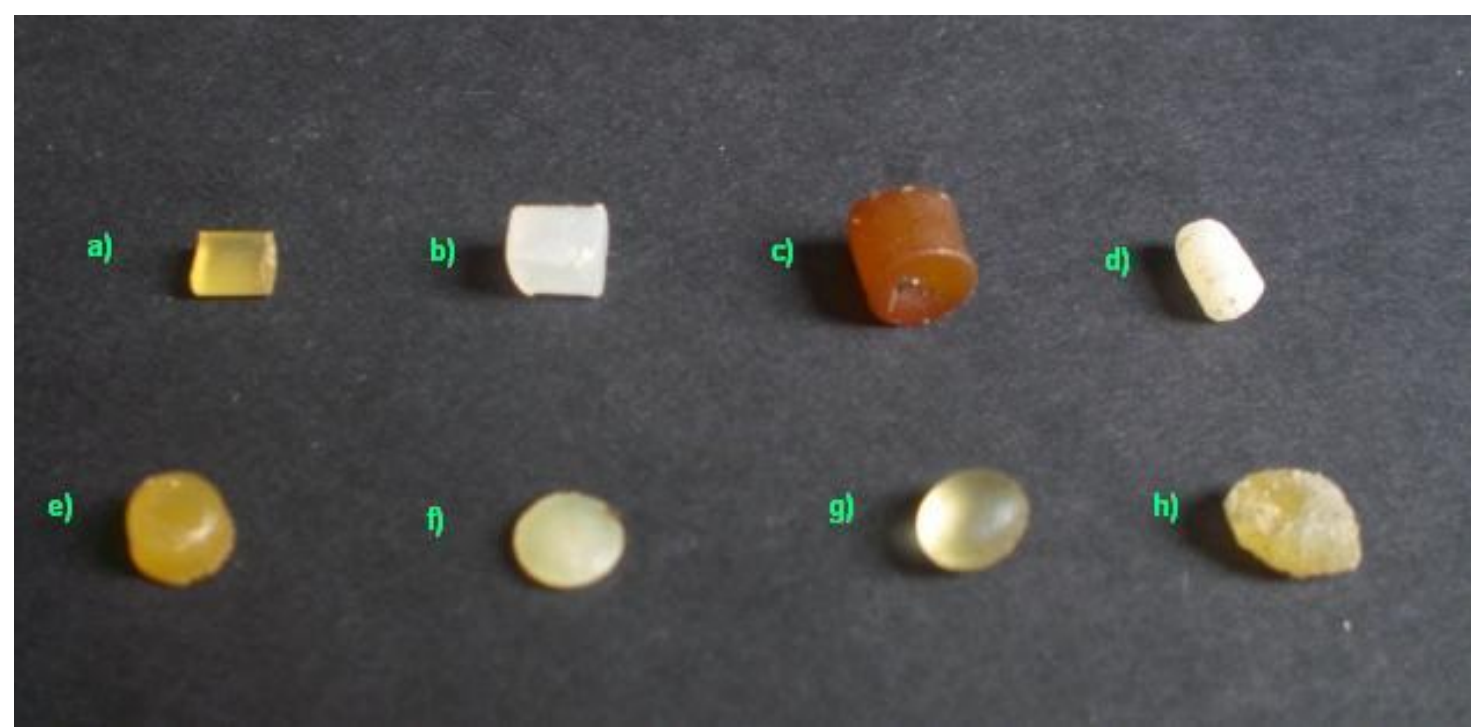

Figura 2. Principais formatos dos pellets coletados na Praia do Tombo, Guarujá, SP, Brasil, outubro de 2012.

Legenda: a) retangular, b) cúbico, c) cilíndrico grosso, c) cilíndrico fino, c) cilíndrico achatado, d) esférico achatado, e) ovoide, e) disforme.

Fonte: 0s autores, 2017.

0 predomínio de pellets no formato cilíndrico achatado parece refletir uma maior demanda de pellets neste formato por parte do mercado consumidor. Pianowski (1997) e Manzano (2009) também observaram que a maior parte dos grânulos encontrados apresentava formato cilíndrico achatado.

Quanto a cor,foram observados 7 principais padrões: branco opaco, branco translúcido, bege translúcido, amarelo translúcido, laranja translúcido, marrom translúcido e preto opaco. A coloração branca translúcida foi a mais frequente (35\%) entre os 463 pellets analisados. Os pellets de cor bege translúcido representaram $27 \%$ da amostra analisada, embora sua porcentagem relativa em cada um dos pontos tenha variado de $18 \%$ a $34 \%$. Estas características de coloração indicam que estes são materiais produzidos recentemente e/ou que foram perdidos no ambiente há pouco tempo e corroboram o predomínio de pellets claros encontrados por Manzano (2009) e Turner e Holmes (2011).

Pellets de cor amarela translúcida representaram de 13\% a 17\% do material analisado, com exceção do ponto $\mathrm{M}$, onde foram encontradas apenas 8 unidades com essa coloração. № entanto, neste ponto foi encontrado o maior número de pellets de cor laranja translúcida, 12 unidades. Nos demais pontos a quantidade de pellets dessa cor variou de 4 a 9 unidades. $0 \mathrm{~s}$ pellets de cor marrom translúcida representaram 5\% do total analisado e estiveram ausentes 
no ponto de coleta D1. Os de cor branca opaca e preta opaca foram os padrões menos observados.

Foram encontrados 35 pellets da amostra analisada com a superfície recoberta por outro material, geralmente de cor preta, o que impossibilitou a identificação de sua cor original. Esse material foi identificado como de coloração indefinida e ocorreu nos pontos M, D1 e D2. A substância que recobria alguns grânulos plásticos, impedindo a identificação de suas cores, era, provavelmente, óleo combustível liberado por navios e barcos. Há referência de caso parecido no trabalho realizado por Turner e Holmes (2011), que encontraram, ocasionalmente, piche em alguns pellets.

A cor amarelada do pellet indica maior tempo flutuando no mar, com o material sujeito ao processo foto-oxidativo causado pela exposição à radiação ultravioleta. Assim, alguns pellets têm coloração que vai do amarelo ao marrom, de acordo com o tempo de exposição ao meio ambiente (END0 et al., 2005; MANZAN0, 2009; TURNER e HOLMES, 2011). Pellets com essas características representaram $26 \%$ do total analisado neste estudo. Devido ao maior tempo que estão no ambiente marinho, estes pellets adsorvem também maior quantidade de poluentes, como os Bifenil Policlorados (PCB)(END0 et al., 2005; IOC/FA0/UNEP, 1989; RIOS, 2007; TURNER e HOLMES, 2011).

\section{CONCLUSÃO}

A Praia do Tombo recebe quantidades consideráveis de pellets plásticos. No estudo realizado, a média diária foi de 220 pellets nos pontos amostrados. Quanto ao formato, foram encontrados 8 tipos, sendo o mais incidente o formato cilíndrico-achatado. Em relação à coloração, obteve-se 7 padrões de cor, sendo o bege translúcido o mais encontrado, indicando uma deposição recente dos pellets.

A deposição contínua de pellets plásticos observada na praia estudada pode ser considerado um fator crítico para o ambiente local no longo prazo, bem como para outras praias sujeitas as mesmas condições de deposição desses resíduos.Por isso, o monitoramento ambiental de áreas costeiras deveria cotejar a poluição e contaminação marinha por pellets 
plásticos em escala local, considerando características oceanográficas e de ocupação de áreas próximas a esse tipo de ambiente.

\section{REFERENNCIAS}

ARAÚUJ0, M. C. B. Resíduos Sólidos em praias do Litoral Sul de Pernambuco: Origens e Consequências. 2003. Dissertação (Mestrado em Ciências) - Programa de Pós-Graduação em 0ceanografia, Universidade Federal de Pernambuco, Recife.

END0, S. et al. Concentration of polychlorinated biphenyls (PCBs) in beached resin pellets: Variability among individual particles and regional differences. Marine Pollution Bulletin, London, v. 50, n. 10, p. 1103-1114, 2005.

ENVIRONMENTAL PROTECTION AGENCY (EPA). Plastic Pellets In The Aquatic Environment: Sources And Recommendations. Environmental Protection Agency, Washington, 1993.

HESKETT, M. et al. Measurement of persistent organic pollutants (POPs) in plastic resin pellets from remote islands: Toward establishment of background concentrations for International Pellet Watch. Marine Pollution Bulletin, London, v. 64, n. 2, p. 445-448, 2012.

HOLMES, L.; TURNER, A.; THOMPSON, R. C. Adsorption of trace metals to plastic resin pellets in the marine environment.Environmental Pollution, v. 160, n. 1, p. 42-48, 2012.

IOC/FA0/UNEP. Report of the IOC/FA0/UNEP review meeting on the persistent synthetic materials pilot survey. Athens: Programme for pollution monitoring and research in the Mediterranean, 1989.

IVAR D0 SUL, J. A. Lixo Marinho na Área de Desova de Tartarugas Marinhas do Litoral Norte da Bahia: conseqüências para o meio ambiente e moradores locais. 2005.Monografia (Graduação em Oceanologia). Departamento de 0ceanografia, Fundação Universidade Federal do Rio Grande, Rio Grande.

LE et al. Temporal and spatial changes in persistent organic pollutants in Vietnamese coastal waters detected from plastic resin pellets. Marine Pollution Bulletin, London, v. 109, n. 1, p. 320-324, 2016.

MANZANO, A. B. Distribuição, taxa de entrada, composição química e identificação de fontes de grânulos plásticos na Enseada de Santos, SP, Brasil.2009. Dissertação (Mestrado em Ciências). Instituto 0ceanográfico, Universidade de São Paulo, São Paulo.

PEREIRA, F. C.; OLIVEIRA, A. L.; TURRA, A. Gestão de resíduos sólidos no ambiente marinho: Pellets Plásticos. V Simpósio Brasileiro de 0ceanografia. Oceanografia e Políticas públicas. Santos, 2011.

PIANOWSKI, F. Resíduos sólidos e esférulas plásticas nas praias do Rio Grande do Sul - Brasil. 1997. Monografia (Graduação em 0ceanologia). Departamento de Oceanografia, Fundação Universidade Federal do Rio Grande, Rio Grande.

RIOS, L. M.; MOORE, J.; J0NES, P. R. Persistent organic pollutants carried by synthetic polymers in the ocean environment. Marine Pollution Bulletin, London, v. 54, p. 1230-1237, 2007.

TANIGUCHI, S. et al. Spatial variability in persistent organic pollutants and polycyclic aromatic hydrocarbons found in beach-stranded pellets along the coast of the state of São Paulo, southeastern Brazil. Marine Pollution Bulletin, London, v. 106, n. 1-2, 15, p. 87-94, 2016.

TOURINHO, P. da S. Ingestão de resíduos sólidos por juvenis de tartaruga-verde (Chelonia mydas) na costa do Rio Grande do Sul, Brasil.2007. Monografia (Graduação em 0ceanologia). Departamento de 0ceanografia, Fundação Universidade Federal do Rio Grande, Rio Grande. 
TURNER, A.; HOLMES, L. Occurrence, distribution and characteristics of beached plastic production pellets on the island of Malta (central Mediterranean). Marine Pollution Bulletin, London, v. 62, n.2, p. 377-81, 2011.

UNEP - UNITED NATIONS ENVIRONMENT PROGRAMME. Marine Litter. An Analytical overview. Nairobi: UNEP, 2005.

USEPA - United STATES ENVIRONMENTAL PROTECTION AGENCY). Plastic Pellets In The Aquatic Environment: Sources And Recommendations. Washington: USEPA, 1993.

WINDOM, H. L. Contamination of the marine environment from land-based sources. Marine Pollution Bulletin, London, v. 25, n. 1-4, p. 32-36, 1992. 